\title{
PTK7 Faces the Wnt in Development and Disease
}

\author{
Hanna Berger ${ }^{1}$, Andreas Wodarz ${ }^{2,3}$ and Annette Borchers ${ }^{1,4 *}$ \\ ${ }^{1}$ Department of Biology, Molecular Embryology, Philipps-Universität Marburg, Marburg, Germany, ${ }^{2}$ Department of Anatomy I, \\ Molecular Cell Biology, University of Cologne, Cologne, Germany, ${ }^{3}$ Cluster of Excellence - Cellular Stress Responses in \\ Aging-Associated Diseases, University of Cologne, Cologne, Germany, ${ }^{4}$ DFG Research Training Group, Membrane Plasticity \\ in Tissue Development and Remodeling, GRK 2213, Philipps-Universität Marburg, Marburg, Germany
}

PTK7 (protein tyrosine kinase 7) is an evolutionarily conserved transmembrane receptor regulating various processes in embryonic development and tissue homeostasis. On a cellular level PTK7 affects the establishment of cell polarity, the regulation of cell movement and migration as well as cell invasion. The PTK7 receptor has been shown to interact with ligands, co-receptors, and intracellular transducers of Wnt signaling pathways, pointing to a function in the fine-tuning of the Wnt signaling network. Here we will review recent findings implicating PTK7 at the crossroads of Wnt signaling pathways in development and disease.

Keywords: PTK7, Wnt signaling, planar cell polarity, cancer, neural tube defect, scoliosis

\section{OPEN ACCESS}

Edited by:

Sigmar Stricker,

Free University of Berlin, Germany

Reviewed by:

Madelon Maurice,

Utrecht University, Netherlands

Frank Thévenod,

Witten/Herdecke University, Germany

*Correspondence:

Annette Borchers

borchers@uni-marburg.de

Specialty section:

This article was submitted to

Signaling,

a section of the journal

Frontiers in Cell and Developmental

Biology

Received: 23 December 2016 Accepted: 21 March 2017

Published: 05 April 2017

Citation:

Berger H, Wodarz A and Borchers A (2017) PTK7 Faces the Wnt in

Development and Disease.

Front. Cell Dev. Biol. 5:31

doi: 10.3389/fcell.2017.00031

\section{INTRODUCTION}

PTK7 (protein tyrosine kinase 7) is an evolutionarily conserved transmembrane receptor with a broad range of functions in tissue development and homeostasis. Originally identified as a gene upregulated in colon carcinoma cells and accordingly named colon carcinoma kinase 4 (CCK-4) (Mossie et al., 1995) it was later shown to affect various aspects of cell-cell communication and movement. PTK7 controls tissue morphogenesis and patterning by affecting cell polarity, migration as well as tissue regeneration and wound healing (Lu et al., 2004; Shnitsar and Borchers, 2008; Caddy et al., 2010; Lee et al., 2011; Lander and Petersen, 2016). Additionally its function in adult tissue homeostasis is demonstrated by the fact that misregulation of PTK7 expression correlates with development of cancer and its progression to metastasis in various cellular contexts (reviewed in Dunn and Tolwinski, 2016). Furthermore, mutations in PTK7 have been implicated in scoliosis and human neural tube closure defects, demonstrating its clinical relevance (Hayes et al., 2014; Wang et al., 2015; Grimes et al., 2016). Since the first publication on PTK7/CCK-4 (Mossie et al., 1995) more than 20 years ago over 120 publications have followed. Although its signaling function is still far from being understood, recent findings provide compelling evidence that PTK7 is a regulator of Wnt signaling pathways. In this review we will summarize recent findings and take a look at PTK7's function in distinct Wnt signaling pathways.

Secreted glycoproteins of the Wnt family are key regulators of development and disease. Wnt ligands regulate a wide range of processes including primary embryonic axis specification, organogenesis and stem cell proliferation. Further, deregulated Wnt signaling has been implicated in various diseases like colon and breast cancer, melanoma, and neurodegenerative disorders (MacDonald et al., 2009; Clevers and Nusse, 2012; Anastas and Moon, 2013; Inestrosa and Varela-Nallar, 2014). Wnt ligands activate distinct downstream signaling pathways, and historically the first described, $B$-catenin-dependent, signaling cascade is referred to as the "canonical" Wnt signaling pathway, while later discovered, B-catenin-independent pathways were termed "non-canonical." Canonical Wnt signaling (Logan and Nusse, 2004; MacDonald et al., 2009) 
is activated by binding of the Wnt ligand to a receptor complex consisting of the seven-pass transmembrane Frizzled $(\mathrm{Fz})$ receptor and the low-density lipoprotein receptor-related protein 6 (LRP6) (MacDonald and He, 2012). Wnt binding to the Fz/LRP6 receptor complex leads to inactivation of glycogen synthase kinase $3 ß$ (GSK3ß) regulating various intracellular substrates. One of these is the transcriptional co-activator $B$ catenin, which is phosphorylated and thereby targeted for proteasomal degradation. Thus, in the presence of Wnt ligands, B-catenin is stabilized, enters the nucleus and regulates in combination with transcription factors of the Lef (lymphoid enhancer-binding factor) and Tcf ( $\mathrm{T}$ cell factor) family the transcription of target genes. In contrast to canonical Wnt signaling, non-canonical Wnt signaling pathways encompass a complex network of signal transducers that do not activate B-catenin, but use alternative modes of downstream signaling (reviewed in Niehrs, 2012). Here, we will focus on the planar cell polarity (PCP) pathway, as PTK7 has been implicated in its regulation.

The PCP pathway (Goodrich and Strutt, 2011; Yang and Mlodzik, 2015) determines the orientation of cells in the plane of an epithelium and is one of the best-characterized noncanonical Wnt signaling pathways. PCP was first described in Drosophila, where genetic screens discovered its function in the polarization of adult cuticular structures. According to mutant phenotypes showing wing hair polarity defects the genes Frizzled (Fz) and Disheveled (Dsh) were identified. Other core PCP proteins include the four-pass transmembrane protein Van Gogh (Vang, Strabismus), the atypical cadherin Flamingo (Fmi, Celsr) and intracellular components like Prickle (Pk) and Diego (Dgo). These proteins confer intra- and intercellular signaling, thereby aligning PCP in neighboring cells. Complementary studies in vertebrates revealed that these core PCP proteins are also required for the polarization of vertebrate tissues, like the orientation of hair follicles in the epidermis or the sensory hair cells in the inner ear (Montcouquiol et al., 2006; Simons and Mlodzik, 2008; Wallingford, 2012). Furthermore, these proteins are also involved in the polarized localization of cilia, microtubule-based protrusions that are found on the surface of most vertebrate cells and required for fluid movement during development and homeostasis (Wallingford, 2010; Wallingford and Mitchell, 2011). In addition to the polarization of tissues, loss of function studies using the mouse, zebrafish and Xenopus model systems demonstrated that PCP signaling also affects morphogenetic cell movements shaping the embryonic body. One of these is convergent extension, a cell movement whereby cells intercalate in a way that a tissue converges in one direction and extends in the perpendicular direction (Wallingford et al., 2002; Wallingford, 2012). Convergent extension is required to drive gastrulation and neural tube closure. Consequently, misregulation of PCP signaling leads to severe gastrulation and neurulation defects in mouse, zebrafish and Xenopus embryos. Since the discovery of vertebrate PCP phenotypes, these have also contributed to the identification of novel vertebrate regulators of PCP without previous knowledge of a Drosophila phenotype. One of these genes, which was identified by its mouse neural tube closure and inner ear hair polarity defect, is PTK7.

\section{PTK7 AFFECTS Wnt SIGNALING PATHWAYS}

Vertebrate PTK7 is according to the current criteria a bona fide PCP regulator. Using a mouse gene trap-screen for transmembrane proteins with a function in neural development, PTK7 mutants were identified showing a combination of severe neural tube closure and inner ear polarity defects (Lu et al., 2004). Based on this mutant phenotype, which is typical for known regulators of PCP (Hamblet et al., 2002; Curtin et al., 2003; Montcouquiol et al., 2003), as well as its genetic interaction with Vangl2, PTK7 was added to the list of vertebrate PCP regulators. Further functional studies using mouse, zebrafish and Xenopus confirmed a function for PTK7 in processes that are regulated by PCP signaling, including convergent extension movements during gastrulation, neurulation and Wolffian duct elongation, as well as neural crest migration and wound healing (Table 1). Surprisingly, although PTK7 appears to be a core regulator of vertebrate PCP, classical PCP phenotypes have so far not been reported for the Drosophila orthologs of PTK7, off-track (otk), and off-track2 (otk2). These two genes, which are the result of a tandem gene duplication, function redundantly in the tubular morphogenesis of the male ejaculatory duct, leading to male sterility in the otk, otk2 double mutant (Linnemannstons et al., 2014). Intriguingly, mesoderm-specific knock-out of PTK7 in the mouse resulted in tubular morphogenesis defects in the Wolffian duct, again leading to male sterility (Xu et al., 2016). In both cases, tubular morphogenesis defects upon loss of Otk/Otk2 or PTK7 may be caused by the failure to properly execute convergent extension movements. Thus, although the Drosophila mutants do not display the classical PCP defects, PTK7/Otk may play an evolutionarily conserved role in the regulation of cell movements.

The molecular mechanism by which PTK7 affects PCP signaling is currently unclear. However, as PTK7 interacts with Wnt ligands and known Wnt receptors (Table 2) it likely affects PCP by functioning as a Wnt receptor. This is also supported by the structure of PTK7, which is highly reminiscent of receptor tyrosine kinases. PTK7 consists of seven extracellular immunoglobulin domains, a transmembrane domain, and an evolutionarily conserved tyrosine kinase homology domain. The kinase homology domain of PTK7 lacks catalytic activity (Miller and Steele, 2000; Kroiher et al., 2001), but serves as an interaction site for intracellular signaling molecules like $ß$-catenin, Dsh, and Src (Shnitsar and Borchers, 2008; Puppo et al., 2011; Andreeva et al., 2014). PTK7 interacts with distinct Wnt receptors including Fz7, LRP6, and Ror2 (Peradziryi et al., 2011; Bin-Nun et al., 2014; Linnemannstons et al., 2014; Martinez et al., 2015; Podleschny et al., 2015), indicating that PTK7 affects canonical and noncanonical Wnt signaling pathways. This is also reflected by its evolutionarily conserved interaction with different Wnt ligands that are supposed to signal via both canonical and non-canonical pathways (Peradziryi et al., 2011; Linnemannstons et al., 2014; Martinez et al., 2015). While its requirement for PCP signaling is firmly established, the function of PTK7 in canonical Wnt signaling remains controversial. PTK7 has been reported to activate canonical Wnt signaling in the context of Spemann's organizer formation (Puppo et al., 2011) and the specification 
TABLE 1 | PCP phenotypes upon PTK7 loss of function in vertebrates.

\begin{tabular}{|c|c|c|c|}
\hline PCP phenotype & Process & Mutant & References \\
\hline \multirow[t]{2}{*}{ Craniorachischisis } & Neural tube closure & Mouse, hypomorphic mutant (Ptk $\left.7^{X S T 87}\right)$ & Lu et al., 2004 \\
\hline & & $\begin{array}{l}\text { Mouse, chuzhoi mutant (insertion of } \\
\text { MT1-MMP splice site) }\end{array}$ & Paudyal et al., 2010 \\
\hline \multirow[t]{6}{*}{ Convergent extension defect } & Neural tube closure & Mouse, hypomorphic mutant (Ptk7 $\left.{ }^{X S T 87}\right)$ & Lu et al., 2004; Williams et al., 2014 \\
\hline & & Xenopus, Morpholino knockdown & Lu et al., 2004; Wehner et al., 2011 \\
\hline & & $\begin{array}{l}\text { Zebrafish, maternal-zygotic mutant } \\
\text { (ptk } 7^{h s c 9} \text { ) }\end{array}$ & Hayes et al., 2013 \\
\hline & Gastrulation & Mouse, hypomorphic mutant (Ptk7 $\left.{ }^{X S T 87}\right)$ & Yen et al., 2009 \\
\hline & & 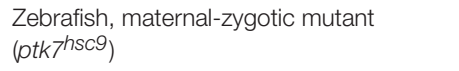 & Hayes et al., 2013 \\
\hline & Wolffian duct morphogenesis & Mouse, hypomorphic mutant (Ptk $\left.7^{X S T 87}\right)$ & Xu et al., 2016 \\
\hline \multirow[t]{2}{*}{$\begin{array}{l}\text { Impaired stereociliary bundle } \\
\text { orientation }\end{array}$} & Development of the organ of corti & Mouse, hypomorphic mutant (Ptk7XST87) & $\begin{array}{l}\text { Lu et al., 2004; Lee et al., 2012; Andreeva } \\
\text { et al., } 2014\end{array}$ \\
\hline & & $\begin{array}{l}\text { Mouse, chuzhoi mutant (insertion of } \\
\text { MT1-MMP splice site) }\end{array}$ & Paudyal et al., 2010 \\
\hline Impaired neural crest migration & Neural crest migration & Xenopus Morpholino knockdown & $\begin{array}{l}\text { Shnitsar and Borchers, 2008; Podleschny } \\
\text { et al., } 2015\end{array}$ \\
\hline Defective wound repair & Epidermal wound repair & Mouse, hypomorphic mutant (Ptk7 XST87) & Caddy et al., 2010 \\
\hline Defect in cilia development & Development of ependymal cell cilia & Zebrafish, zygotic mutant (ptk $7^{h s c 9}$ ) & Grimes et al., 2016 \\
\hline
\end{tabular}

TABLE 2 | PTK7 interaction partners with a known function in Wnt signaling.

\begin{tabular}{|c|c|c|c|c|}
\hline \multicolumn{2}{|c|}{ Interaction partner } & \multirow{2}{*}{$\begin{array}{l}\text { Interaction domain } \\
\text { Extracellular domain }\end{array}$} & \multirow{2}{*}{$\begin{array}{l}\text { Biological context } \\
\text { Xenopus double axis assay }\end{array}$} & \multirow{2}{*}{$\begin{array}{l}\text { References } \\
\text { Peradziryi et al., } 2011\end{array}$} \\
\hline Wnt ligand & Wnt3a, Wnt8 & & & \\
\hline & Wnt4 & Unknown & Xenopus double axis assay & Peradziryi et al., 2011 \\
\hline & Wnt5a & $\begin{array}{l}\text { Extracellular domain } \\
(\lg 4-7)\end{array}$ & Xenopus morphogenesis & Martinez et al., 2015 \\
\hline & Wnt2 & Unknown & Drosophila male fertility & Linnemannstons et al., 2014 \\
\hline \multirow[t]{5}{*}{ Wnt receptor } & Fz1 & Unknown & Drosophila male fertility & Linnemannstons et al., 2014 \\
\hline & Fz2 & Unknown & Drosophila male fertility & Linnemannstons et al., 2014 \\
\hline & $\mathrm{Fz7}$ & Extracellular domain & Xenopus luciferase reporter assay & Peradziryi et al., 2011 \\
\hline & Ror2 & $\begin{array}{l}\text { Extracellular domain } \\
\lg 1-7\end{array}$ & $\begin{array}{l}\text { Xenopus morphogenesis and neural crest } \\
\text { migration }\end{array}$ & Martinez et al., 2015; Podleschny et al., 2015 \\
\hline & LRP6 & $\begin{array}{l}\text { Transmembrane } \\
\text { domain }\end{array}$ & Xenopus posterior neural development & Bin-Nun et al., 2014 \\
\hline \multirow[t]{2}{*}{ Intracellular Wnt components } & Dsh & $\begin{array}{l}\text { Kinase homology } \\
\text { domain (via Rack1/ } \\
\text { PKC } \delta 1 \text { ) }\end{array}$ & $\begin{array}{l}\text { Xenopus neural crest migration and neural } \\
\text { tube closure }\end{array}$ & Shnitsar and Borchers, 2008; Wehner et al., 2011 \\
\hline & $\beta$-catenin & $\begin{array}{l}\text { Kinase homology } \\
\text { domain }\end{array}$ & Xenopus Spemann Organizer formation & Puppo et al., 2011 \\
\hline
\end{tabular}

of posterior neural tissue (Bin-Nun et al., 2014) in Xenopus embryos. However, PTK7 inhibits canonical Wnt signaling in Xenopus double axis and luciferase reporter assays (Peradziryi et al., 2011). This was confirmed by $p t k 7$ mutant zebrafish, which showed an upregulation of $ß$-catenin target gene expression, suggesting that PTK7 functions in attenuating canonical Wnt signaling (Hayes et al., 2013). Conflicting results were also obtained analyzing the interaction of PTK7 with Wnt ligands using immunoprecipitation of overexpressed/tagged constructs. While we found interaction of PTK7 with canonical Wnt3a and
Wnt8 but not non-canonical Wnt5a (Peradziryi et al., 2011) in Xenopus lysates, Martinez et al. observed an interaction with non-canonical Wnt5a, but not canonical Wnt1 (Martinez et al., 2015) in HEK293T cells. Some of these contradictions may be explained by receptor context. Using secreted proteins we showed that the extracellular domain of PTK7 requires the extracellular Fz7 domain for interaction with recombinant Wnt3a (Peradziryi et al., 2011). Conversely, Wnt5a binding may require the Ror2 co-receptor. Although Martinez et al. confirmed interaction of PTK7 and Wnt5a in cells that were 
depleted of Ror2 using a specific siRNA, there may still be sufficient endogenous Ror2 present to mediate binding. Thus, studies analyzing direct interaction of PTK7 and Wnt ligands are currently lacking. Furthermore, experiments testing Wnt binding of combinatorial PTK7 co-receptor complexes are required. As PTK7 is a versatile receptor interacting not only with Wnt coreceptors but also with plexin and VEGF receptors (reviewed in Peradziryi et al., 2012), the latter interactions may also contribute to tissue-specific differences. Thus, future research will have to elucidate how receptor context affects PTK7 signaling and its functions in distinct Wnt signaling pathways.

\section{PTK7 AND DISEASE}

As PTK7 has a crucial function in the regulation of Wnt signaling pathways known to be essential for embryonic development and homeostasis, mutations in the human PTK7 gene are likely of clinical relevance. PTK7 was identified as a gene upregulated in colon carcinoma cells and appears to be misregulated in a variety of cancers (Dunn and Tolwinski, 2016). Furthermore, PTK7 mutations have recently been implicated in the etiology of neural tube defects and scoliosis (Hayes et al., 2014; Wang et al., 2015). Here, we will briefly describe these respective disorders and look at the human PTK7 gene variants identified in this context as well as their functional implications.

The connection between PTK7 and cancer has so far mostly been deduced on the basis of up- or downregulation of PTK7 in a variety of cancer types. PTK7 levels were reported to be increased in esophageal (Shin et al., 2013), gastric (Lin et al., 2012), colorectal (Lhoumeau et al., 2015), breast (Gartner et al., 2014), intrahepatic bile duct (Jin et al., 2014), prostate (Zhang et al., 2014), and lung carcinoma (Chen et al., 2014), as well as liposarcoma (Gobble et al., 2011). In other cancer types PTK7 was shown to be downregulated, including lung squamous cell carcinoma (Kim et al., 2014), ovarian carcinoma (Wang et al., 2014) and metastatic melanoma (Easty et al., 1997). While the mechanistic contribution of PTK7 to the respective tumor phenotypes is unclear at present, the upregulation of PTK7 in many tumor types makes it an attractive tumor marker and therapeutic target. Indeed, the first PTK7 specific reagents with potential clinical applications have now been published, including a PTK7-specific fluorescently labeled aptamer for in vivo detection of tumor tissue (Calzada et al., 2017). Very interestingly, PTK7 has recently been established as a marker for normal colon stem cells (Jung et al., 2015) and as a marker for tumor initiating cells in triple-negative breast cancer, ovarian cancer and non-small cell lung cancer (Damelin et al., 2017). The authors of the latter study also developed a PTK7-targeted antibody-drug conjugate and showed that its application reduces tumor initiating cells and induces sustained tumor regressions, paving the way for a PTK7-directed anti-tumor therapy (Damelin et al., 2017).

Neural tube defects are among the most common human birth defects affecting 1 per 1000 live births and are caused by environmental as well as genetic factors (Wilde et al., 2014). PCP genes are likely among the genetic factors contributing to the etiology of human neural tube closure defects as loss of function mutants of PTK7, Vangl, Celsr, Fz, Dvl, and Scribble result in the most severe neural tube closure defects called craniorachischisis (Gerrelli and Copp, 1997; Kibar et al., 2001; Hamblet et al., 2002; Curtin et al., 2003; Murdoch et al., 2003; Lu et al., 2004; Wang et al., 2006), whereby the neural tube fails to close from the midbrain-hindbrain boundary to the base of the spine. Indeed, rare mutations with a predicted damaging role were identified for a number of PCP genes including Vangl1/2, Celsr1, Fzd6, Dvl2, Prickle, and Scribble (Kibar et al., 2007; De Marco et al., 2014). Furthermore, the analysis of a cohort of 473 patients with various forms of neural tube defects identified six rare PTK7 sequence variants (Wang et al., 2015). Interestingly, five of these mutations are located in the extracellular domain of PTK7, which serves as interaction site for Wnt ligands as well as Fz7 and Ror2 receptors (Table 2; Peradziryi et al., 2011; Martinez et al., 2015; Podleschny et al., 2015). Whether these interactions are affected in the potentially pathogenic sequence variants is currently unclear and functional validation assays testing their efficiency to rescue for example Xenopus or zebrafish loss of function phenotypes are still missing. Nevertheless, the extracellular domain was shown to be important for promoting PCP and inhibiting canonical Wnt signaling. In fact, deletion of the extracellular domain abolished PTK7's ability to inhibit canonical Wnt signaling in Xenopus reporter assays (Peradziryi et al., 2011). Conversely, a membranetethered PTK7 extracellular fragment was sufficient to rescue excess Wnt/ß-catenin signaling and PCP morphogenesis defects in maternal-zygotic ptk7 mutant zebrafish (Hayes et al., 2013). Thus, these data point to PTK7 as a risk factor for neural tube closure defects and stress the functional importance of its extracellular domain.

In addition to neural tube defects, PTK7 has also been implicated in the pathogenesis of scoliosis, a complex genetic disorder characterized by a three-dimensional spinal curvature. Congenital scoliosis (CS) is apparent at birth and involves abnormal vertebrae development, while idiopathic scoliosis is diagnosed during adolescence and does not show vertebral malformations. Ptk7 mutant zebrafish were recently discovered as a model for congenital and idiopathic scoliosis. Maternalzygotic ptk7 (MZptk7) mutant zebrafish exhibit vertebral abnormalities at larval stages, phenotypically resembling congenital scoliosis. Further, zygotic $p t k 7$ (Zptk7) mutants show late onset spinal curvatures consistent with the idiopathic form of scoliosis (Hayes et al., 2014). Analysis of maternal-zygotic mutants showed that PTK7 positively regulates PCP-dependent morphogenesis, while it attenuates $ß$-catenin-dependent canonical Wnt signaling (Hayes et al., 2013). Thus, segmentation and somite patterning are disturbed, likely causing the observed vertebral abnormalities. In contrast, zygotic $p t k 7$ mutants did not show defects in segmentation and somite patterning, but developed late spinal curvatures resembling idiopathic scoliosis (Hayes et al., 2014; Grimes et al., 2016). They showed defects in ependymal cell cilia development leading to irregularities in the cerebrospinal fluid (CSF) flow. Moreover, the brain ventricles revealed a severe hydrocephalus, a condition associated with loss of cilia function. Consistently, the number of motile cilia was reduced and if cilia were present they lacked the correct 
polarization. Transgenic reintroduction of wild-type PTK7 in motile ciliated cell lineages rescued all phenotypes, proving a specific function of PTK7 in motile ciliated cells. The authors hypothesized that impaired cerebrospinal fluid flow due to abnormal cilia function is most likely the cause of scoliosis in ptk7-deficient zebrafish (Grimes et al., 2016). The connection of PTK7 to scoliosis was further evidenced by the isolation of a novel PTK7 mutation from a single patient suffering from idiopathic scoliosis. This mutation, hPTK $7^{\mathrm{P} 545 \mathrm{~A}}$, exhibits a proline to alanine substitution in the sixth extracellular immunoglobulin domain thereby affecting PCP and canonical Wnt signaling function (Hayes et al., 2014). In fact, in contrast to wild-type human PTK7, the hPTK7 ${ }^{\mathrm{P} 545 \mathrm{~A}}$ failed to rescue PCP-dependent axial extension defects as well as nervous system patterning defects caused by Wnt8 overexpression (Hayes et al., 2014). Further, the mutant protein accumulated at the plasma membrane, indicating altered protein stability and/or trafficking of this mutant compared to the wild-type protein. As PTK7 forms co-receptor complexes with Fz7 and LRP6 (Peradziryi et al., 2011; Bin-Nun et al., 2014; Linnemannstons et al., 2014), which were shown to be subject to Wnt-dependent receptor complex trafficking (Yamamoto et al., 2006; Kim et al., 2008; Ohkawara et al., 2011), this is likely also the case for PTK7containing receptor complexes. Thus, it is tempting to speculate that the proline residue in position 545-which is conserved in mammals-is required for interaction with Wnt ligands or coreceptors, respectively. Interestingly, this conserved P545 residue is also mutated in one of the six sequence variants identified in patients with neural tube closure defects. In a patient affected with myelomeningocele and interestingly also hydrocephalus,

\section{REFERENCES}

Anastas, J. N., and Moon, R. T. (2013). WNT signalling pathways as therapeutic targets in cancer. Nat. Rev. Cancer 13, 11-26. doi: 10.1038/nrc3419

Andreeva, A., Lee, J., Lohia, M., Wu, X., Macara, I. G., and Lu, X. (2014). PTK7-Src signaling at epithelial cell contacts mediates spatial organization of actomyosin and planar cell polarity. Dev. Cell 29, 20-33. doi: 10.1016/j.devcel.2014.02.008

Bin-Nun, N., Lichtig, H., Malyarova, A., Levy, M., Elias, S., and Frank, D. (2014). PTK7 modulates Wnt signaling activity via LRP6. Development 141, 410-421. doi: 10.1242/dev.095984

Caddy, J., Wilanowski, T., Darido, C., Dworkin, S., Ting, S. B., Zhao, Q., et al. (2010). Epidermal wound repair is regulated by the planar cell polarity signaling pathway. Dev. Cell 19, 138-147. doi: 10.1016/j.devcel.2010.06.008

Calzada, V., Moreno, M., Newton, J., Gonzalez, J., Fernandez, M., Gambini, J. P., et al. (2017). Development of new PTK7-targeting aptamer-fluorescent and radiolabelled probes for evaluation as molecular imaging agents: lymphoma and melanoma in vivo proof of concept. Bioorg. Med. Chem. 25, 1163-1171. doi: 10.1016/j.bmc.2016.12.026

Chen, R., Khatri, P., Mazur, P. K., Polin, M., Zheng, Y., Vaka, D., et al. (2014). A meta-analysis of lung cancer gene expression identifies PTK7 as a survival gene in lung adenocarcinoma. Cancer Res. 74, 2892-2902. doi: 10.1158/0008-5472.CAN-13-2775

Clevers, H., and Nusse, R. (2012). Wnt/beta-Catenin signaling and disease. Cell 149, 1192-1205. doi: 10.1016/j.cell.2012.05.012

Curtin, J. A., Quint, E., Tsipouri, V., Arkell, R. M., Cattanach, B., Copp, A. J., et al. (2003). Mutation of Celsr1 disrupts planar polarity of inner ear hair cells and causes severe neural tube defects in the mouse. Curr. Biol. 13, 1129-1133. doi: 10.1016/S0960-9822(03)00374-9 which is indicative of a cilia-defect, the non-polar proline residue was changed to a positively charged arginine (Wang et al., 2015). These data indicate that this conserved residue is important for protein function and mutations are likely pathogenic. Future studies are required to elucidate the molecular pathomechanism.

\section{CONCLUSIONS}

During the last two decades our understanding of the function of PTK7 has significantly advanced. Diverse biological processes that are regulated by PTK7 have been identified and its role in the establishment of polarity and coordinated cell movements has been acknowledged. Recent publications shed light on a literary "complex" function of PTK7 in Wnt signaling. While its role in non-canonical PCP signaling has been confirmed in different animal model systems and biological contexts, its function with respect to canonical Wnt signaling remains controversial. Possibly, these contradictory findings can be explained by the cell type-specific formation and subcellular localization of distinct co-receptor complexes. Further characterization of the formation and dynamics of these ligand-receptor complexes may help us to understand how PTK7 affects development as well as diseaserelated processes.

\section{AUTHOR CONTRIBUTIONS}

$\mathrm{AB}$ conceptualized and wrote the main part of the paper. AW wrote the Drosophila and the cancer section and edited the manuscript; HB wrote the section on scoliosis and designed the two tables.

Damelin, M., Bankovich, A., Bernstein, J., Lucas, J., Chen, L., Williams, S., et al. (2017). A PTK7-targeted antibody-drug conjugate reduces tumor-initiating cells and induces sustained tumor regressions. Sci. Trans. Med. 9:eaag2611. doi: 10.1126/scitranslmed.aag2611

De Marco, P., Merello, E., Piatelli, G., Cama, A., Kibar, Z., and Capra, V. (2014). Planar cell polarity gene mutations contribute to the etiology of human neural tube defects in our population. Birth Defects Res. A Clin. Mol. Teratol. 100, 633-641. doi: 10.1002/bdra.23255

Dunn, N. R., and Tolwinski, N. S. (2016). Ptk7 and Mcc, unfancied components in non-canonical wnt signaling and cancer. Cancers 8:E68. doi: $10.3390 /$ cancers 8070068

Easty, D. J., Mitchell, P. J., Patel, K., Florenes, V. A., Spritz, R. A., and Bennett, D. C. (1997). Loss of expression of receptor tyrosine kinase family genes PTK7 and SEK in metastatic melanoma. Int. J. Cancer 71, 1061-1065. doi: 10.1002/(SICI)1097-0215(19970611)71:6<1061::AID-IJC24>3.0.CO;2-F

Gartner, S., Gunesch, A., Knyazeva, T., Wolf, P., Hogel, B., Eiermann, W., et al. (2014). PTK 7 is a transforming gene and prognostic marker for breast cancer and nodal metastasis involvement. PLOS ONE 9:e84472. doi: 10.1371/journal.pone.0084472

Gerrelli, D., and Copp, A. J. (1997). Failure of neural tube closure in the looptail (Lp) mutant mouse: analysis of the embryonic mechanism. Brain Res. Dev. Brain Res. 102, 217-224. doi: 10.1016/S0165-3806(97)00099-0

Gobble, R. M., Qin, L. X., Brill, E. R., Angeles, C. V., Ugras, S., O’Connor, R. B., et al. (2011). Expression profiling of liposarcoma yields a multigene predictor of patient outcome and identifies genes that contribute to liposarcomagenesis. Cancer Res. 71, 2697-2705. doi: 10.1158/0008-5472.CAN-10-3588

Goodrich, L. V., and Strutt, D. (2011). Principles of planar polarity in animal development. Development 138, 1877-1892. doi: 10.1242/dev.054080 
Grimes, D. T., Boswell, C. W., Morante, N. F., Henkelman, R. M., Burdine, R. D., and Ciruna, B. (2016). Zebrafish models of idiopathic scoliosis link cerebrospinal fluid flow defects to spine curvature. Science 352, 1341-1344. doi: 10.1126/science.aaf6419

Hamblet, N. S., Lijam, N., Ruiz-Lozano, P., Wang, J., Yang, Y., Luo, Z., et al. (2002). Dishevelled 2 is essential for cardiac outflow tract development, somite segmentation and neural tube closure. Development 129, 5827-5838. doi: 10.1242/dev.00164

Hayes, M., Gao, X., Yu, L. X., Paria, N., Henkelman, R. M., Wise, C. A., et al. (2014). ptk7 mutant zebrafish models of congenital and idiopathic scoliosis implicate dysregulated Wnt signalling in disease. Nat. Commun. 5:5777. doi: $10.1038 /$ ncomms5777

Hayes, M., Naito, M., Daulat, A., Angers, S., and Ciruna, B. (2013). Ptk7 promotes non-canonical Wnt/PCP-mediated morphogenesis and inhibits Wnt/betacatenin-dependent cell fate decisions during vertebrate development. Development 140, 1807-1818. doi: 10.1242/dev.090183

Inestrosa, N. C., and Varela-Nallar, L. (2014). Wnt signaling in the nervous system and in Alzheimer's disease. J. Mol. Cell Biol. 6, 64-74. doi: 10.1093/jmcb/mjt051

Jin, J., Ryu, H. S., Lee, K. B., and Jang, J. J. (2014). High expression of protein tyrosine kinase 7 significantly associates with invasiveness and poor prognosis in intrahepatic cholangiocarcinoma. PLoS ONE 9:e90247. doi: 10.1371/journal.pone.0090247

Jung, P., Sommer, C., Barriga, F. M., Buczacki, S. J., Hernando-Momblona, X., Sevillano, M., et al. (2015). Isolation of human colon stem cells using surface expression of PTK7. Stem Cell Rep. 5, 979-987. doi: 10.1016/j.stemcr.2015.10.003

Kibar, Z., Torban, E., McDearmid, J. R., Reynolds, A., Berghout, J., Mathieu, M., et al. (2007). Mutations in VANGL1 associated with neural-tube defects. New Engl. J. Med. 356, 1432-1437. doi: 10.1056/NEJMoa060651

Kibar, Z., Vogan, K. J., Groulx, N., Justice, M. J., Underhill, D. A., and Gros, P. (2001). Ltap, a mammalian homolog of Drosophila Strabismus/Van Gogh, is altered in the mouse neural tube mutant Loop-tail. Nat. Gen. 28, 251-255. doi: $10.1038 / 90081$

Kim, G. H., Her, J. H., and Han, J. K. (2008). Ryk cooperates with Frizzled 7 to promote Wnt11-mediated endocytosis and is essential for Xenopus laevis convergent extension movements. J. Cell Biol. 182, 1073-1082. doi: $10.1083 /$ jcb. 200710188

Kim, J. H., Kwon, J., Lee, H. W., Kang, M. C., Yoon, H. J., Lee, S. T., et al. (2014). Protein tyrosine kinase 7 plays a tumor suppressor role by inhibiting ERK and AKT phosphorylation in lung cancer. Oncol. Rep. 31, 2708-2712. doi: 10.3892/or.2014.3164

Kroiher, M., Miller, M. A., and Steele, R. E. (2001). Deceiving appearances: signaling by "dead" and "fractured" receptor protein-tyrosine kinases. Bioessays 23, 69-76. doi: 10.1002/1521-1878(200101)23:1<69::AID-BIES1009>3.3. $\mathrm{CO} ; 2-\mathrm{B}$

Lander, R., and Petersen, C. P. (2016). Wnt, Ptk7, and FGFRL expression gradients control trunk positional identity in planarian regeneration. Elife 5:e12850. doi: 10.1056/NEJMoa060651

Lee, J., Andreeva, A., Sipe, C. W., Liu, L., Cheng, A., and Lu, X. (2012). PTK7 regulates myosin II activity to orient planar polarity in the mammalian auditory epithelium. Curr. Biol. 22, 956-966. doi: 10.1016/j.cub.2012.03.068

Lee, H. K., Chauhan, S. K., Kay, E., and Dana, R. (2011). Flt-1 regulates vascular endothelial cell migration via a protein tyrosine kinase-7-dependent pathway. Blood 117, 5762-5771. doi: 10.1182/blood-2010-09-306928

Lhoumeau, A. C., Martinez, S., Boher, J. M., Monges, G., Castellano, R., Goubard, A., et al. (2015). Overexpression of the promigratory and prometastatic PTK7 receptor Is associated with an adverse clinical outcome in colorectal cancer. PLoS ONE 10:e0123768. doi: 10.1371/journal.pone.0123768

Lin, Y., Zhang, L. H., Wang, X. H., Xing, X. F., Cheng, X. J., Dong, B., et al. (2012). PTK7 as a novel marker for favorable gastric cancer patient survival. J. Surg. Oncol. 106, 880-886. doi: 10.1002/jso.23154

Linnemannstons, K., Ripp, C., Honemann-Capito, M., Brechtel-Curth, K., Hedderich, M., and Wodarz, A. (2014). The PTK7-related transmembrane proteins off-track and off-track 2 are co-receptors for Drosophila Wnt2 required for male fertility. PLoS Genet. 10:e1004443. doi: 10.1371/journal.pgen.1004443

Logan, C. Y., and Nusse, R. (2004). The Wnt signaling pathway in development and disease. Ann. Rev. Cell Dev.
Biol. 20, 781-810. doi: 10.1146/annurev.cellbio.20.010403. 113126

Lu, X., Borchers, A. G., Jolicoeur, C., Rayburn, H., Baker, J. C., and TessierLavigne, M. (2004). PTK7/CCK-4 is a novel regulator of planar cell polarity in vertebrates. Nature 430, 93-98. doi: 10.1038/nature02677

MacDonald, B. T., and He, X. (2012). Frizzled and LRP5/6 receptors for Wnt/beta-catenin signaling. Cold Spring Harb. Perspect. Biol. 4:a007880. doi: 10.1101/cshperspect.a007880

MacDonald, B. T., Tamai, K., and He, X. (2009). Wnt/beta-catenin signaling: components, mechanisms, and diseases. Dev. Cell 17, 9-26. doi: 10.1016/j.devcel.2009.06.016

Martinez, S., Scerbo, P., Giordano, M., Daulat, A. M., Lhoumeau, A. C., Thome, V., et al. (2015). The PTK7 and ROR2 protein receptors interact in the vertebrate WNT/Planar Cell Polarity (PCP) Pathway. J. Biol. Chem. 290, 30562-30572. doi: 10.1074/jbc.M115.697615

Miller, M. A., and Steele, R. E. (2000). Lemon encodes an unusual receptor protein-tyrosine kinase expressed during gametogenesis in Hydra. Dev. Biol. 224, 286-298. doi: 10.1006/dbio.2000.9786

Montcouquiol, M., Crenshaw, E. B. III, and Kelley, M. W. (2006). Noncanonical Wnt signaling and neural polarity. Ann. Rev. Neurosci. 29, 363-386. doi: 10.1146/annurev.neuro.29.051605.112933

Montcouquiol, M., Rachel, R. A., Lanford, P. J., Copeland, N. G., Jenkins, N. A., and Kelley, M. W. (2003). Identification of Vangl2 and Scrb1 as planar polarity genes in mammals. Nature 423, 173-177. doi: 10.1038/nature01618

Mossie, K., Jallal, B., Alves, F., Sures, I., Plowman, G. D., and Ullrich, A. (1995). Colon carcinoma kinase- 4 defines a new subclass of the receptor tyrosine kinase family. Oncogene 11, 2179-2184.

Murdoch, J. N., Henderson, D. J., Doudney, K., Gaston-Massuet, C., Phillips, H. M., Paternotte, C., et al. (2003). Disruption of scribble (Scrb1) causes severe neural tube defects in the circletail mouse. Hum. Mol. Genet. 12, 87-98. doi: $10.1093 / \mathrm{hmg} / \mathrm{ddg} 014$

Niehrs, C. (2012). The complex world of WNT receptor signalling. Nat. Rev. Mol. Cell Biol. 13, 767-779. doi: 10.1038/nrm3470

Ohkawara, B., Glinka, A., and Niehrs, C. (2011). Rspo3 binds syndecan 4 and induces Wnt/PCP signaling via clathrin-mediated endocytosis to promote morphogenesis. Dev. Cell 20, 303-314. doi: 10.1016/j.devcel.2011.01.006

Paudyal, A., Damrau, C., Patterson, V. L., Ermakov, A., Formstone, C., Lalanne, Z., et al. (2010). The novel mouse mutant, chuzhoi, has disruption of Ptk7 protein and exhibits defects in neural tube, heart and lung development and abnormal planar cell polarity in the ear. BMC Dev. Biol. 286, 20970-20976. doi: 10.1186/1471-213X-10-87

Peradziryi, H., Kaplan, N. A., Podleschny, M., Liu, X., Wehner, P., Borchers, A., et al. (2011). PTK7/Otk interacts with Wnts and inhibits canonical Wnt signalling. EMBO J. 30, 3729-3740. doi: 10.1038/emboj.2011.236

Peradziryi, H., Tolwinski, N. S., and Borchers, A. (2012). The many roles of PTK7: a versatile regulator of cell-cell communication. Arch. Biochem. Biophys. 524, 71-76. doi: 10.1016/j.abb.2011.12.019

Podleschny, M., Grund, A., Berger, H., Rollwitz, E., and Borchers, A. (2015). A PTK7/Ror2 Co-receptor complex affects xenopus neural crest migration. PLoS ONE 10:e0145169. doi: 10.1371/journal.pone.0145169

Puppo, F., Thome, V., Lhoumeau, A. C., Cibois, M., Gangar, A., Lembo, F., et al. (2011). Protein tyrosine kinase 7 has a conserved role in Wnt/beta-catenin canonical signalling. EMBO Rep. 12, 43-49. doi: 10.1038/embor.2010.185

Shin, W. S., Kwon, J., Lee, H. W., Kang, M. C., Na, H. W., Lee, S. T., et al. (2013). Oncogenic role of protein tyrosine kinase 7 in esophageal squamous cell carcinoma. Cancer Sci. 104, 1120-1126. doi: 10.1111/cas.12194

Shnitsar, I., and Borchers, A. (2008). PTK7 recruits dsh to regulate neural crest migration. Development 135, 4015-4024. doi: 10.1242/dev.023556

Simons, M., and Mlodzik, M. (2008). Planar cell polarity signaling: from fly development to human disease. Ann. Rev. Genet. 42, 517-540. doi: 10.1146/annurev.genet.42.110807.091432

Wallingford, J. B. (2010). Planar cell polarity signaling, cilia and polarized ciliary beating. Curr. Opin. Cell Biol. 22, 597-604. doi: 10.1016/j.ceb.2010.07.011

Wallingford, J. B. (2012). Planar cell polarity and the developmental control of cell behavior in vertebrate embryos. Ann. Rev. Cell Dev. Biol. 28, 627-653. doi: 10.1146/annurev-cellbio-092910-154208

Wallingford, J. B., Fraser, S. E., and Harland, R. M. (2002). Convergent extension: the molecular control of polarized cell movement during 
embryonic development. Dev. Cell 2, 695-706. doi: 10.1016/S1534-5807(02) 00197-1

Wallingford, J. B., and Mitchell, B. (2011). Strange as it may seem: the many links between Wnt signaling, planar cell polarity, and cilia. Genes Dev. 25, 201-213. doi: 10.1101/gad.2008011

Wang, H., Li, G., Yin, Y., Wang, J., Wei, W., Guo, Q., et al. (2014). PTK7 protein is decreased in epithelial ovarian carcinomas with poor prognosis. Int. J. Clin. Exp. Pathol. 7, 7881-7889.

Wang, M., De Marco, P., Merello, E., Drapeau, P., Capra, V., and Kibar, Z. (2015). Role of the planar cell polarity gene Protein tyrosine kinase 7 in neural tube defects in humans. Birth Defects Res. A Clin. Mol. Teratol. 103, 1021-1027. doi: 10.1002/bdra.23422

Wang, Y., Guo, N., and Nathans, J. (2006). The role of Frizzled3 and Frizzled6 in neural tube closure and in the planar polarity of inner-ear sensory hair cells. $J$. Neurosci. 26, 2147-2156. doi: 10.1523/JNEUROSCI.4698-05.2005

Wehner, P., Shnitsar, I., Urlaub, H., and Borchers, A. (2011). RACK1 is a novel interaction partner of PTK7 that is required for neural tube closure. Development 138, 1321-1327. doi: 10.1242/dev.056291

Wilde, J. J., Petersen, J. R., and Niswander, L. (2014). Genetic, epigenetic, and environmental contributions to neural tube closure. Ann. Rev. Genet. 48, 583-611. doi: 10.1146/annurev-genet-120213-092208

Williams, M., Yen, W., Lu, X., and Sutherland, A. (2014). Distinct apical and basolateral mechanisms drive planar cell polarity-dependent convergent extension of the mouse neural plate. Dev. Cell 29, 34-46. doi: 10.1016/j.devcel.2014.02.007

Xu, B., Washington, A. M., Domeniconi, R. F., Ferreira Souza, A. C., Lu, X., Sutherland, A., et al. (2016). Protein tyrosine kinase 7 is essential for tubular morphogenesis of the Wolffian duct. Dev. Biol. 412, 219-233. doi: 10.1016/j.ydbio.2016.02.029

Yamamoto, H., Komekado, H., and Kikuchi, A. (2006). Caveolin is necessary for Wnt-3a-dependent internalization of LRP6 and accumulation of beta-catenin. Dev. Cell 11, 213-223. doi: 10.1016/j.devcel.2006.07.003

Yang, Y., and Mlodzik, M. (2015). Wnt-Frizzled/planar cell polarity signaling: cellular orientation by facing the wind (Wnt). Ann. Rev. Cell Dev. Biol. 31, 623-646. doi: 10.1146/annurev-cellbio-100814-125315

Yen, W. W., Williams, M., Periasamy, A., Conaway, M., Burdsal, C., Keller, R., et al. (2009). PTK7 is essential for polarized cell motility and convergent extension during mouse gastrulation. Development 136, 2039-2048. doi: 10.1242/dev.030601

Zhang, H., Wang, A., Qi, S., Cheng, S., Yao, B., and Xu, Y. (2014). Protein tyrosine kinase 7 (PTK7) as a predictor of lymph node metastases and a novel prognostic biomarker in patients with prostate cancer. Int. J. Mol. Sci. 15, 11665-11677. doi: $10.3390 /$ ijms 150711665

Conflict of Interest Statement: The authors declare that the research was conducted in the absence of any commercial or financial relationships that could be construed as a potential conflict of interest.

Copyright (c) 2017 Berger, Wodarz and Borchers. This is an open-access article distributed under the terms of the Creative Commons Attribution License (CC BY). The use, distribution or reproduction in other forums is permitted, provided the original author(s) or licensor are credited and that the original publication in this journal is cited, in accordance with accepted academic practice. No use, distribution or reproduction is permitted which does not comply with these terms. 